\title{
PEMANFAATAN LIGNIN KRAFT DARI LINDI HITAM SEBAGAI PEREKAT KAYU KOMPOSIT
}

\author{
Adi Santoso* \\ *Peneliti Puslitbang Hasil Hutan Bogor \\ E-mail: Adisant04@Yahoo.com
}

\begin{abstract}
Utilization of Kraft Lignin from black liquor as adhesives in the wood composite.
\end{abstract}

The lignin in the sulphate black liquor (known as kraft lignin) has a strong affinity when being reacted with formaldehyde to form lignin formaldehyde adhesives. To increase the bonding strength, the lignin is copolymerized with phenol or resorcinol to form lignin phenol formaldehyde or lignin resorcinol formaldehyde resins. The resins can be applied in of reconstituted wood products manufacturing such as plywood, fingerjointed wood assembly and glue laminated lumber. The research result showed that each type of lignin based adhesives had specific characters which met Indonesian standard. The test result on plywood which glued by lignin formaldehyde $(L F)$ and lignin phenol formaldehyde $(L P F)$ indicated that bonding strength of the products were $8.0-27.0 \mathrm{~kg} / \mathrm{cm}^{2}$, for a while on laminated wood which glued by lignin resorcinol formaldehyde $(L R F)$ indicated that bonding strength of the products were $36.9-88.0 \mathrm{~kg} / \mathrm{cm}^{2}$, modulus of rupture and modulus of elasticity was $372-637 \mathrm{~kg} / \mathrm{cm}^{2}$ and $47,164-60,237 \mathrm{~kg} / \mathrm{cm}^{2}$, respectively. The formaldehyde emissions were about 0.05-0.14 mg/L. The efficiency of lignin based adhesives on finger joint application reach at 35.4-73.6\%. Therefore, the synthesis of lignin based adhesives, an unique wood adhesive with good resin characteristics and met bonding strength and formaldehyde emission requirement as stated in Japanese standard.

Keywords : Kraft lignin, composite wood, adhesives

\begin{abstract}
ABSTRAK
Lignin dalam lindi hitam (dikenal sebagai lignin kraft) memiliki afinitas yang kuat bila direaksikan dengan formaldehida membentuk perekat lignin formaldehida. Guna meningkatkan daya rekatnya, lignin dikopolimerisasi dengan phenol atau resorsinol sehingga terbentuk resin lignin phenol formaldehida atau lignin resorsinol formaldehida. Resin tersebut dapat diaplikasikan dalam pembuatan produk kayu rekonstitusi seperti kayu lapis, papan sambung dan kayu lamina. Hasil penelitian menunjukkan bahwa setiap jenis perekat berbasis lignin memiliki karakter yang spesifik yang memenuhi persyaratan standar Indonesia. Hasil pengujian terhadap kayu lapis yang direkat dengan lignin formaldehida (LF) dan lignin phenol formaldehida (LPF) menunjukkan bahwa keteguhan rekat produk tersebut berkisar antara $8,0-27,0 \mathrm{~kg} / \mathrm{cm}^{2}$, sementara untuk kayu lamina yang direkat dengan lignin resorsinol formaldehida (LRF) berkisar antara $36,9-88,0 \mathrm{~kg} / \mathrm{cm}^{2}$, dengan modulus of rupture dan modulus of elasticity berturut-turut sekitar $372-637 \mathrm{~kg} / \mathrm{cm}^{2}$ dan $47,164-60,237 \mathrm{~kg} / \mathrm{cm}^{2}$. Emisi formaldehida produk berkisar antara 0,05-0,14 $\mathrm{mg} / \mathrm{L}$. Efisiensi perekat berbasis lignin pada aplikasi papan sambung mencapai $35,4-73,6 \%$. Produk yang menggunakan perekat berbasis lignin ini memenuhi persyaratan Jepang.
\end{abstract}

Kata kunci : Lignin Kraft, kayu majemuk, perekat

\section{PENDAHULUAN}

Di Indonesia sampai dengan tahun 2005 diprediksi terdapat 32 pabrik pulp yang ada di Indonesia dengan kapasitas produksi pulp sampai dengan mencapai 7,6 juta ton (Ahmad 2001). Berdasarkan studi di lapangan diketahui bahwa dari produksi 250 ton pulp per hari, diperoleh lindi hitam sebanyak 120 ton per hari atau 43.800 ton per tahun (48\%) (Santoso 2003).
Banyaknya lignin yang bisa diperoleh dari lindi hitam adalah sekitar $18-47 \%$ (b/b) (Rudatin 1989, Lewis dan Lantzy 1985), dan bila dihitung lebih lanjut, maka dari 7,6 juta ton pulp itu bisa diperoleh lindi hitam kira - kira 3,6 juta ton, dengan perolehan lignin sekitar $0,65-1,7$ juta ton.

Isolat lignin dari lindi hitam, memiliki tiga gugus fungsi, yaitu gugus karbonil, hidroksifenolik, dan hidroksil- 
benzilik. Menurut Sjöström (1995), di antara ketiga gugus fungsi tersebut gugus hidroksifenolik berperan penting dalam reaksi yang menggunakan katalis alkali terutama dalam pemanfaatan lignin sebagai bahan baku perekat untuk kayu lapis melalui reaksi hidroksimetilasi (Pizzi 1983, Gillespie 1985, dan Santoso et al. 1995) maupun kopolimerisasi dengan fenol (Santoso et al., 2001).

Dalam hal aplikasinya sebagai perekat, resin lignin resorsinol formaldehida dapat berikatan secara spesifik dengan kayu karena resin tersebut bersifat polar, yang dicirikan antara lain oleh adanya gugus hidroksil $(\mathrm{OH})$ dan karbonil (CO) (Wake dalam Garrat, 1964). Di lain pihak salah satu komponen kayu adalah selulosa, yang mengandung gugus hidroksil dan karbonil sehingga bersifat polar. Berdasarkan keserupaan sifat tersebut, Pizzi (1983) mengemukakan bahwa perekat bereaksi dengan selulosa membentuk ikatan yang kuat.

Tulisan ini mengemukakan tentang aplikasi lignin teknis yang diperoleh dari lindi hitam sisa pemasakan di pabrik pulp untuk perekat kayu, yang diharapkan dapat dijadikan alternative dan mengurangi kebergantungan akan perekat impor untuk industri pengolahan kayu yang ramah lingkungan.

\section{BAHAN DAN METODE}

\section{Bahan dan Alat}

Bahan yang dipakai dalam penelitian ini adalah lindi hitam kraft cair yang berasal dari pabrik kertas PT Bekasi Teguh-Bekasi dengan bahan baku campuran serpih kayu sengon (Paraserianthes falcataria (L) Nielsen) dan manii (Maesopsis eminii Engl.) dengan nisbah bobot 60:40, berbentuk cairan kental, berwarna cokelat kehitaman, dan berbau khas senyawa sulfur. Bahan kimi antara lain terdiri atas $\mathrm{H}_{2} \mathrm{SO}_{4} 2 \mathrm{~N}, \mathrm{NaOH} 0,1 \mathrm{~N}$, phenol, resorsinol, dan formaldehida

\section{Pembuatan Perekat Lignin}

Lignin dari lindi hitam diisolasi dengan cara pengendapan berulang (represipitasi), yaitu mengendapkan lindi hitam dengan larutan $\mathrm{H}_{2} \mathrm{SO}_{4} 2 \mathrm{~N}$, kemudian disaring. Endapan lignin yang terbentuk kemudian dilarutkan dengan $\mathrm{NaOH} 0,1 \mathrm{~N}$ dan disaring. Filtrat diendapkan kembali dengan larutan $\mathrm{H}_{2} \mathrm{SO}_{4} 2 \mathrm{~N}$ dan disaring lagi. Hasil yang didapat kemudian dikeringkan pada suhu $50-60^{\circ} \mathrm{C}$ (Kim et al. 1987).

Lignin direaksikan dengan reaktan yang diperlukan seperti phenol, resorsinol, dan formaldehida pada perbandingan mol tertentu. Untuk perekat kayu lapis, dibuat perekat lignin formaldehida (LF) dengan nisbah mol $\mathrm{L}: \mathrm{F}=1: 2$ dan lignin phenol formaldehida (LPF) dengan nisbah mol $\mathrm{L}: \mathrm{P}: \mathrm{F}=1: 0,5: 2$, sementara untuk papan sambung dibuat dengan perekat lignin pada nisbah mol L:R:F = 1:0,5:2. Sifat fisikokoimia perekat berbasis lignin tersebut selanjutnya diuji meliputi $\mathrm{pH}$, kadar padatan, bobot jenis dan kekentalan (SNI 1998).

\section{Pembuatan kayu komposit}

Kayu lapis dibuat dari jenis kayu tusam (Pinus merkusii) dengan ukuran 30 $\mathrm{cm} \times 30 \mathrm{~cm} \times 4.5 \mathrm{~mm}$, menggunakan perekat LF dan LPF, dan dikempa pada suhu $135^{\circ} \mathrm{C}$ selama 15 menit.

Kayu lamina dibuat dari tiga jenis kayu yaitu manii (Maesopsis eminii), jati (Tectona grandis), dan kempas (Koompassia malaccensis) dengan ukuran masing-masing $50 \times 2 \times 5 \mathrm{~cm}$. Setiap jenis kayu lamina tersebut menggunakan perekat LRF dan dikempa pada suhu kamar.

Perekat LRF ini juga diaplikasikan pada pembuatan papan sambung dengan kempa dingin pada lima jenis kayu, yaitu Waru (Hibiscus titiaccus), Bunyo (Trioma malaccensis), Gambir (Trigono pleura malayana), Tempeas (Teymanniodendron sympliciodes), dan Rasamala (Altingia excelsa).

Kualitas rekat dan efisiensi penyambungan dari setiap produk di atas diuji dengan mengacu kepada SNI (2000) 
(untuk papan sambung dan kayu lapis) dan JAS (2003) (untuk kayu lamina).

\section{HASIL DAN PEMBAHASAN}

Karakter perekat berbasis lignin tercantum pada Tabel 1. Secara umum, semua jenis perekat lignin yang dibuat memenuhi persyaratan SNI untuk perekat berbasis fenolik (SNI 1998).

\section{Kayu lapis dan kayu lamin}

Keteguhan rekat dari setiap jenis produk disajikan pada Tabel 2 dan Tabel 3. Nilai keteguhan rekat kayu lapis yang menggunakan perekat LF, LPF dan LRF semuanya memenuhi persyaratan SNI untuk tipe eksterior, karena nilainya $>8$ $\mathrm{kg} / \mathrm{cm}^{2}$. Sementara aplikasi perekat LRF (1-3) pada tiga jenis kayu lamina masingmasing jenis kayu manii, jati dan kempas menghasilkan keteguhan rekat yang lebih tinggi dibandingkan dengan produk serupa yang menggunakan perekat komersial seperti phenol-, resorsinol, serta phenol resorsinol formaldehida, seperti Aerodux 500, Cony Bond KR 15Y and PA 302. Keteguhan rekat kayu lamina hasil penelitian ini juga sebanding dengan hasil penelitian dari Tahir et al. (1988), Karnasudirdja (1989), dan Sadiyo (1989) Masa kempa 6 - 12 jam menghasilkan modulus of elasticity (MOE) dan modulus of rupture (MOR) lebih tinggi dibanding kayu utuhnya, namun masa kempa selama 3 jam lebih rendah. Nilai MOR dan MOE lebih besar dibandingkan hasil penelitian Sadiyo (1989). Hasil tersebut menunjukkan bahwa formula LRF cocok untuk penggunaan kayu lamina.

\section{Papan Sambung}

Lignin resorsinol formaldehida (LRF) diaplikasikan pula pada papan sambung. Hasil penelitian terhadap 5 jenis kayu untuk papan sambung yang direkat dengan LRF mencapai efisiensi sambungan antara 35.4-73.6\% (Tabel 4).

Produk perekatan yang menggunakan perekat LRF yang dihasilkan dalam penelitian ini ergolong tipe eksterior, yang ramah lingkungan karena emisi formaldehidanya di bawah ketentuan maksimum yang diperkenankan standar Amerika (NPA, 1983) (0,3 mg/L) dan Jepang (JAS, 2003) $(0,3-4,2 \mathrm{mg} / \mathrm{L})$.

Berdasarkan hasil perhitungan, jika dibandingkan dengan perekat komer-sial seperti phenol formaldehida (PF), perekat berbasis lignin ini lebih murah. Untuk meproduksi perekat PF diperlukan bahan baku seperti phenol sebanyak $45 \%$ dan formaldehida $27 \%$ dari total komponennya, sementara untuk membuat perekat PRF diperlukan phenol sebanyak 27\%, resorsinol $19 \%$ dan formaldehida $35 \%$, namun untuk memproduksi perekat berbasis lignin seperti lignin resorsinol formaldehida (LRF) hanya diperlukan lignin sebanyak $20 \%$, resorsinol $8 \%$ dan formaldehida $13 \%$.

\section{KESIMPULAN DAN SARAN}

Setiap jenis perekat liginin memiliki karakter tersendiri yang masing-masing memenuhi persyaratan standar Indonesia. Hasil pengujian terhadap kayu lapis yang direkat dengan lignin formaldehiyda dan lignin phenol formaldehida menunjukkan bahwa keteguhan rekat produk tersebut berkisar antara 8,02 - 26,96 kg/ $\mathrm{cm}^{2}$, sementara untuk kayu lamina yang direkat dengan lignin resorsinol formaldehida berkisar antara $36,86-88,00 \mathrm{~kg} / \mathrm{cm}^{2}$, modulus of rupture dan modulus of elasticity $371,66-637,45 \mathrm{~kg} / \mathrm{cm}^{2}$ dan 47.164,38-60.236,71 $\mathrm{kg} / \mathrm{cm}^{2}$. Emisi formaldehidanya berkisar antara 0,05 $0,14 \mathrm{mg} / \mathrm{L}$. Efisiensi sambungan dari perekat berbasis lignin untuk aplikasi papan sambung mencapai 35,4-73,6\%.

Perekat sintetis berbasis lignin merupakan perekat prospektif, yang unik dengan karakteristik resinnya yang memenuhi keteguhan rekat dan emisi formaldehida standar Jepang. Produk perekatan yang menggunakan perekat berbasis lignin ini selain berkualitas eksterior, juga ramah lingkungan dan lebih ekonomis dibandingkasn dengan perekat phenol formaldehida, resorsinol formaldehida, dan phenol resorsinol formaldehida. 
Tabel 1. Ikhtisar Karakteristik Perekat Berbasis Lignin

\begin{tabular}{|c|c|c|c|c|c|c|c|}
\hline \multirow[b]{2}{*}{ No. } & \multirow[b]{2}{*}{ Sifat } & \multicolumn{4}{|c|}{ Jenis perekat lignin } & \multirow{2}{*}{$\begin{array}{l}\text { Standar PF } \\
\text { (SNI, 1998) }\end{array}$} & \multirow{2}{*}{$\begin{array}{c}\text { PRF } \\
\text { (Aczonobe, } \\
\text { 2003) }\end{array}$} \\
\hline & & LF & LPF & LRF (1) & LRF (2) & & \\
\hline 1. & Visual & $\begin{array}{l}\mathrm{L}, \\
\mathrm{RB}\end{array}$ & $\begin{array}{l}\mathrm{L}, \\
\mathrm{RB}\end{array}$ & $\mathrm{L}, \mathrm{RB}$ & $\mathrm{L}, \mathrm{RB}$ & $\mathrm{L}, \mathrm{RB}$ & $\mathrm{L}, \mathrm{RB}$ \\
\hline 2 & $\begin{array}{l}\text { Specific } \\
\text { gravity }\end{array}$ & 1,12 & 1,06 & 1,14 & 1,16 & $>1,0$ & 1,15 \\
\hline 3. & $\begin{array}{l}\text { Solid content, } \\
(\%)\end{array}$ & 42 & 54 & 50,28 & 52,78 & $\begin{array}{l}40,0- \\
45,00\end{array}$ & 57,03 \\
\hline 4. & $\begin{array}{l}\text { Viscosity } \\
\text { (Poise) }\end{array}$ & 1,4 & 2,4 & 1,8 & 1,2 & $1,3-3,0$ & 3,4 \\
\hline 5. & Acidity (pH) & 8,1 & 8,5 & 10,75 & 9,85 & $\begin{array}{l}10,0- \\
13,01\end{array}$ & 8,0 \\
\hline er & $\begin{aligned} n: & L F \\
& \operatorname{LRF}(1) \\
& \\
& \operatorname{LRF}(2)\end{aligned}$ & $\begin{array}{l}=\text { lign } \\
=\quad \text { lign } \\
\\
=\text { mer } \\
=\text { lion }\end{array}$ & forn & $\begin{array}{l}\text { ehida, } \\
\text { nol for } \\
\text { atan }\end{array}$ & $=\operatorname{lign}$ & $\begin{array}{l}\text { kenol form } \\
\text { kau lap }\end{array}$ & $\begin{array}{l}\text { ehida } \\
L R B\end{array}$ \\
\hline
\end{tabular}

Tabel 2. Kualitas Rekat Produk Kayu Komposit yang Menggunakan Perekat Berbasis Lignin

\begin{tabular}{|c|c|c|c|c|}
\hline \multirow[b]{2}{*}{$\begin{array}{c}\text { Jenis perekat } \\
\text { lignin }\end{array}$} & \multirow[b]{2}{*}{ Produk } & \multicolumn{2}{|c|}{ Keteguhan rekat $\left(\mathrm{kg} / \mathrm{cm}^{2}\right)$} & \multirow{2}{*}{$\begin{array}{c}\text { Emisi } \\
\text { formaldehida } \\
(\mathrm{mg} / \mathrm{L})\end{array}$} \\
\hline & & Uji kering & Uji basah & \\
\hline $\begin{array}{l}\text { Lignin } \\
\text { formaldehida }\end{array}$ & Kayu lapis* & - & $8.88-26.96$ & - \\
\hline $\begin{array}{l}\text { Lignin phenol } \\
\text { formaldehida }\end{array}$ & Kayu lapis $* *$ & - & $10.07-19.25$ & - \\
\hline $\begin{array}{l}\text { Lignin Resorcinol } \\
\text { formaldehida }\end{array}$ & Kayu lapis $* * *$ & - & $8.02-9.05$ & $0.02-0.05$ \\
\hline $\begin{array}{l}\text { Lignin Resorsinol } \\
\text { formaldehida (1) }\end{array}$ & Kayu lamina ${ }^{a}$ & $76.64-79.02$ & $36.86-44.64$ & $0.002-0.140$ \\
\hline $\begin{array}{l}\text { Lignin Resorsinol } \\
\text { formaldehida (2) }\end{array}$ & Kayu lamina ${ }^{b}$ & $66.56-72.00$ & $42.40-45.73$ & - \\
\hline $\begin{array}{l}\text { Lignin Resorsinol } \\
\text { formaldehida (3) }\end{array}$ & Kayu lamina $^{c}$ & $69.12-88.00$ & $43.17-45.49$ & $0.010-0.014$ \\
\hline
\end{tabular}

Keterangan:

* kempa panas $\left(135^{\circ} \mathrm{C}\right), 3$ menit, jenis kayu tusam dengan ekstender ; - tak ada data

** kempa panas $\left(135^{\circ} \mathrm{C}\right), 3$ menit, jenis kayu tusam tanpa ekstender

*** kempa dingin (suhu kamar), 24 jam, jenis kayu tusam tanpa ekstender ${ }^{a}$ kempa dingin, 3 jam, , jenis kayu manii; ${ }^{b}$ kempa dingin, 4 jam jenis kayu jati ${ }^{c}$ kempa dingin, 8 jam, jenis kayu kempas

Tabel 3. Ikhtisar Nilai MOE dan MOR dari Kayu Lamina Manii Berperekat LRF

\begin{tabular}{ccccc}
\hline \multirow{2}{*}{$\begin{array}{c}\text { Masa kempa } \\
\text { (jam) }\end{array}$} & \multicolumn{2}{c}{ MOE $\left(\mathrm{kg} / \mathrm{cm}^{2}\right)$} & \multicolumn{2}{c}{ MOR $\left(\mathrm{kg} / \mathrm{cm}^{2}\right)$} \\
\cline { 2 - 5 } & Kayu lamina & Kayu utuh & Kayu lamina & Kayu utuh \\
\hline 3 & $47.164,38$ & & 371,66 & \\
6 & $68.540,24$ & $56.387,72$ & 476,95 & 462,57 \\
12 & $60.236,71$ & & 637,45 & \\
\hline
\end{tabular}


Tabel 4. Ikhtisar Ffisiensi Sambungan pada Lima Jenis Papan Sambung

\begin{tabular}{clcccc}
\hline No. & Jenis kayu & Bobot jenis & $\begin{array}{c}\text { MOR } \\
\left(\mathrm{kg} / \mathrm{cm}^{2}\right)\end{array}$ & $\begin{array}{c}\text { MOE } \\
\left(\mathrm{kg} / \mathrm{cm}^{2}\right)\end{array}$ & $\begin{array}{c}\text { Efisiensi } \\
\text { sambungan }(\%)\end{array}$ \\
\hline 1. & Waru & 0,40 & 501 & 65.869 & 60,3 \\
2. & Bunyo & 0,47 & 470 & 151.692 & 66,6 \\
3. & Gambir & 0,58 & 400 & 74.261 & 40,5 \\
4. & Tempeas & 0,76 & 399 & 146.417 & 73,6 \\
5. & Rasamala & 0,77 & 404 & 91.502 & 35,4 \\
\hline
\end{tabular}

\section{DAFTAR PUSTAKA}

Achmadi S S. 1990. Kimia Kayu. Depdikbud. Dirjen Pendidikan Tinggi. Bogor: PAU Ilmu Hayat, IPB.

Akzonobel. 2001. Synteko PhenolResorcinol Adhesive 1711 with Hardeners 2620, 2622, 2623. Jakarta: Casco Adhesive.

Gardner D J dan R L Anido. 2002. Adhesion Between Wood and Fiber Reinforced Polymers: Bonding Issues. http: // WWW.umaine.edu./ adhesion / gardner/ 5502002 / wood-frp \% 20 adhesion.pdf. Diakses 8 Januari, 2003.

Japanese Agricultural Standard (JAS). 2003. Japanese Agricultural Standard for Glued Laminated Timber. Notification No. 234 February 27,2003. Tokyo: JPIC.

Karnasudirdja S. 1989. Prospek Kayu Indonesia sebagai Bahan Baku Industri Kayu Lamina. Makalah pada Seminar Glue Laminated Timber (Glulam), 15 Juni 1989, Departemen Kehutanan RI. Jakarta.

Kim, H., M. K. Hill and A. L. Friche. 1987. Preparation of Kraft Lignin from Black Liquor. Tappi Journal, December 1987: 112 .
National Particleboard Association (NPA). 1983. Small Scale Test Method for Determining Formaldehyde from Wood Product, Two hours Desicator Test. Maryland.

Pizzi A. 1983. Wood Adhesives: Chemistry and Technology. New York: Marcel Dekker.

Pizzi A. 1994. Advanced Wood Adhesives Technology. New York: Marcel Dekker.

Sadiyo, S. 1989. Pengaruh kombinasi jenis kayu dan jenis perekat terhadap sifat fisis dan mekanis panel diagonal lambung kapal. Fakultas Pascasarjana, IPB - Bogor. Thesis. (Tidak diterbitkan).

Santoso A. 2003. Sintesis dan karakterisasi resin lignin resorsinol formaldehida untuk perekat kayu lamina. Fakultas PascasarjanaInstitut Pertanian Bogor. Disertasi (tidak diterbitkan).

Standar Nasional Indonesia (SNI). 1998. Kumpulan SNI Perekat. Jakarta: Badan Standardisasi Nasional.

Tahir P Md, M H Sahri, Z Ashari. 1998. Gluability of Less Used and Fast Growing Tropical Plantation Hardwood Species. Selangor: Faculty of Forestry University Pertanian Malaysia. 